TecnoLógicas

ISSN-p 0123-7799

ISSN-e 2256-5337

Vol. 20, No. 40, pp. 139-153

Sep-dic de 2017

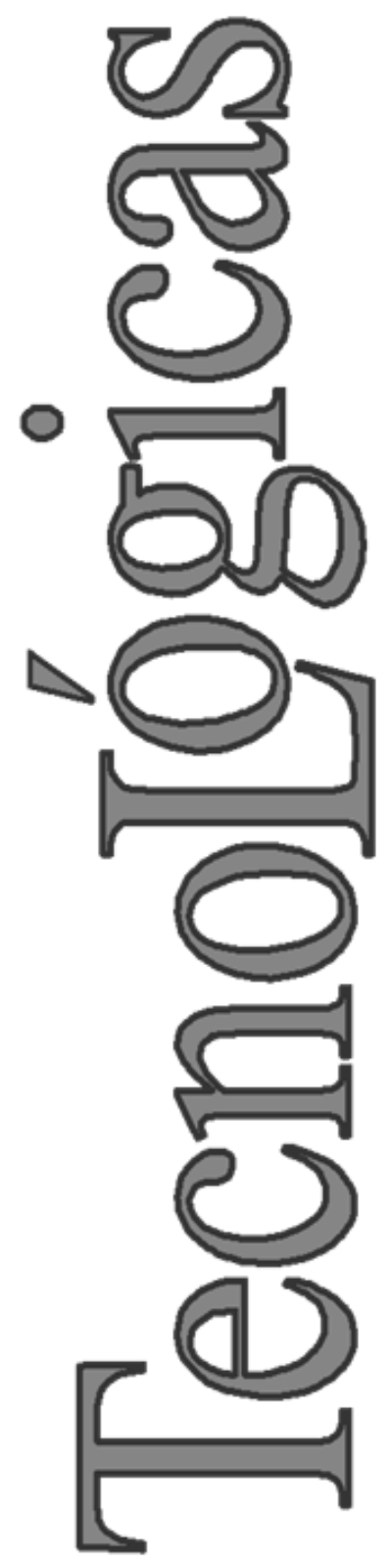

(C) Copyright 2015 por autores y Tecno Lógicas Este trabajo está licenciado bajo una Licencia Internacional Creative Commons Atribución (CC BY)

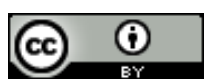

\section{The roles of nanotechnology and internet of nano things in healthcare transformation}

\section{Los roles de la nanotecnología e internet de nano elementos en la transformación de la salud}

\author{
Mirjana Maksimovićc ${ }^{1}$
}

Recibido: 09 de junio de 2017

Aceptado: 28 de agosto de 2017

Cómo citar / How to cite

M. Maksimović, The roles of nanotechnology and internet of nano things in healthcare transformation. TecnoLógicas, vol. 20, no. 40, pp. 139-153, 2017.

$\mathrm{PhD}$ in Technical Sciences (Electrical Engineering-Telecommunication), Faculty of Electrical Engineering, University of East Sarajevo, East Sarajevo, Bosnia and Herzegovina, mirjana@etf.unssa.rs.ba 


\begin{abstract}
Healthcare, as a basic human right, did not remain immune to innovative technologies. Technological progress has significantly contributed to high-quality, on-time, acceptable and affordable healthcare. Since their appearance, nanotechnology and the Internet of Nano Things (IoNT) have continuously affected healthcare and have a tremendous influence on its transformation, contributing to the better outcome. The inclusion of nanotechnology in medicine through nanomaterials and nanodevices, known as nanomedicine, has brought numerous benefits in disease prevention, diagnosis, and treatment. Going further by connecting nanodevices to the Internet, the IoNT paradigm has been created. The inclusion of IoNT concepts in healthcare has resulted in more personalized, timely, and convenient health monitoring and treatment. Hence, nanotechnology and the IoNT hold the potential to completely revolutionize healthcare in the $21^{\text {st }}$ Century, creating a system that will enable early disease detection and diagnosis followed by accurate, on-time and effective treatment with significantly reduced healthcare costs. This paper presents the roles of nanotechnology and IoNT in medicine and healthcare, and attempts to gain an insight of nanoscale solutions and approaches, highlighting benefits and discussing potential risks and concerns. Despite concerns regarding nanotoxicity, privacy and security issues, it is anticipated that nanotechnology and IoNT will show their full potential in medicine and healthcare in the years to come.
\end{abstract}

\title{
Keywords
}

Nanotechnology, nanomedicine, IoNT, healthcare, nanotoxicity.

\section{Resumen}

La salud, como derecho humano básico, no ha permanecido inmune a las tecnologías innovadoras. El progreso tecnológico ha contribuido significativamente a un servicio de salud de alta calidad, aceptable y asequible. Desde su aparición, la nanotecnología y el Internet de las Nanocosas (IoNT, por sus siglas en inglés) han cambiado la atención médica y han influenciado tremendamente su transformación para obtener mejores resultados. La inclusión de la nanotecnología en medicina a través de nanomateriales y nanodispositivos se conoce como nanomedicina. Esta ha brindado numerosos beneficios a la prevención, diagnóstico y tratamiento de enfermedades. Al ir más allá y conectar los nanodispositivos a Internet, nació el paradigma del IoNT. La inclusión de conceptos del IoNT en los servicios de salud ha resultado en monitoreo y tratamiento más personalizados, oportunos y convenientes. Por estos motivos, la nanotecnología y el IoNT tienen el potencial para revolucionar completamente la asistencia médica en el siglo XXI, creando un sistema que permitirá la detección y diagnóstico tempranos de enfermedades, seguidos por un tratamiento preciso, oportuno y efectivo con costos significativamente menores. Este artículo presenta el papel que la nanotecnología y el IoNT tienen en medicina y los servicios de salud. Además, intenta ampliar el conocimiento sobre las soluciones y enfoques a nanoescala, resaltando los beneficios y analizando los riesgos y preocupaciones potenciales. A pesar de los miedos relacionados con la nanotoxicidad y privacidad, se anticipa que la nanotecnología y el IoNT muestren todo su potencial en el campo de la medicina y la salud en los próximos años.

\section{Palabras clave}

Nanotecnología, nanomedicina, IoNT, servicio de salud, nanotoxicidad. 


\section{INTRODUCTION}

As a technology that has enabled science and engineering on the $10^{-9}$ scale, nanotechnology has resulted in the development of nanoparticles, nanomaterials, nanoscale electronic and sensing devices, and it is considered to be the technology of the $21^{\text {st }}$ Century. Technological advances have enabled nanodevices, composed of nanocomponents, to perform simple tasks such as sensing or actuation and to be connected to the Internet through seamless communication and information transmission. This technological progress has created a vision, namely the Internet of Nano Things (IoNT) [1], which combined with the advancements in nanotechnology will revolutionize almost every field of our lives.

Nanotechnology and the IoNT already have significant roles in numerous applications across diverse sectors, such as agriculture and food, environment protection, electronics, energy and biomedicine, among others. Their widespread utilization in medicine and healthcare holds the potential to bring the greatest benefits to the society, creating a new generation of medicine, known as nanomedicine. According to [2], nanomedicine can be simply defined as applying nanotechnology to biology in medical applications. The more detailed definition states that nanomedicine is an interdisciplinary scientific discipline that involves medicine, physics, biology, chemistry, engineering and optics for disease diagnostic and treatment processes by means of nanotechnology [2]-[4]. Empowering nanomedicine with the IoNT will make revolutionizing changes in disease prevention, diagnosis, and treatment. In other words, the ability to detect and make a diagnosis at the early stage of the disease, precise and effective treatment, the promise to cure the life-threatening diseases, saving a great number of lives as well as extended average lifespan justify the worldwide attention to nanotechnology and IoNT research and development [5].

As it is anticipated that in the next few years there will be no aspect of life untouched by nanotechnology and the IoNT, they receive growing worldwide attention. New and enhanced properties and functionalities are the results of production of novel nanomaterials and nanodevices. This means that the new ways to synthesize nanoparticles and create nanomaterials [6]-[20], the analysis of nanoparticles' and nanomaterials' potential toxicity [12], [20][30], the development of novel nanodevices, nanosensors and nanocommunication [13], [18], [20],[31]-[35], and the implementation of green practices in nanotechnology and the IoNT [11], [24],[36]-[41] are some of the current most interesting topics to research. The particular interest in nanotechnology and the IoNT consists in the fact that they have opened a whole new world of potential remarkable improvements in medicine and healthcare. In addition, it is forecasted that the global nanotechnology market will grow at a CAGR (Compound Annual Growth Rate) of around $17 \%$ during the 2017-2024 period, while the IoNT and nanomedicine markets will grow at a CAGR of $22.81 \%$ from 2016 to 2020 , and $12.3 \%$ from 2013 to 2019 , respectively [26], [42]. These facts will consequently lead to potentially huge revenue based on the commercialization of nanotechnology and the IoNT.

All the above-stated facts justify the increasing interest in research devoted to the implementation of nanotechnology and the IoNT in medicine and healthcare. For that reason, this paper presents an attempt to obtain as much knowledge and insight as possible regarding this topic. For reviewing the roles of nanotechnology and the IoNT in healthcare transformation, a systematic search of relevant literature was conducted on the following online databases: EBSCO, Scopus and Science Direct. In addition, Google Scholar and Research Gate were also used as appropriate subject-related 
information sources. However, the scientific papers used in this survey are by no means exhaustive and they have been used for illustrating, as much as possible, the current state of the application of nanotechnology and the IoNT in healthcare. As the review is aimed at analyzing the roles and benefits nanotechnology advancements bring in medicine and healthcare, a combination of quantitative and qualitative research methodologies was implemented. The review of papers related to nanotechnology, nanomedicine, the IoNT and their correlations have more clearly shown the importance of innovative nanotechnology approaches in medicine and healthcare. One of the main contributions of the performed survey is the SWOT (Strengths, Weaknesses, Opportunities, and Threats) analysis, which helps to thoroughly understand the roles of nanotechnology and the IoNT in healthcare transformation. Despite the weaknesses and risks (mostly related to potential toxicity of nanomaterials, privacy and security issues of the IoNT), the stated benefits-patienttailored, accurate, on-time, accessible and affordable healthcare-justify the necessity for further development and innovations in nanomedicine. There are also numerous opportunities for nanotechnology and the IoNT, powered by medicine and healthcare, that will undoubtedly lead to further benefits and the revolutionization of healthcare. Therefore, the rest of the paper is structured as follows. Section 2 highlights nanotechnology applications in medicine, while Section 3 is devoted to the IoNT paradigm implementation for healthcare purposes. The benefits of nanotechnology and the IoNT, as well as the challenges, risks, and concerns regarding their implementation in medicine and healthcare, are discussed in Section 4. This section also presents the SWOT analysis of nanotechnology and IoNT utilization in healthcare transformation. Finally, the last section presents concluding remarks and future possible directions in nanotech- nology and IoNT applications in the next generation of medicine and healthcare.

\section{NANOMEDICINE AS MEDICINE OF THE FUTURE}

Nanomedicine may be defined as the use of nanodevices and nanostructures for monitoring, repairing or controlling human biological systems at the molecular level. Engineered nanodevices and nanostructures used in medicine and healthcare can be classified into 4 categories:

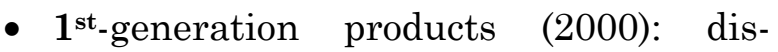
persed and contact nanostructures (e.g., colloids) as well as product incorporating nanostructures (e.g., nanostructured metal, polymers).

- $2^{\text {nd }}$-generation active nanostructures (2000-2005): physical-chemical active adaptive structures (e.g., actuators, amplifiers) and bio-active devices (e.g., biodevices, targeted drugs).

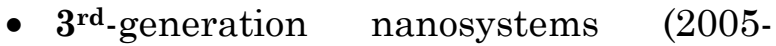
2010): robotics, evolutionary biosystems.

- $4^{\text {th-generation }}$ molecular nanotechnology and nanosystems (2010-2020): molecular devices by design and molecular structures that could serve as a foundation for regeneration or replacement of lost body parts.

Nanomedicine currently utilizes a variety of nanomaterials and nanodevices designed to perform certain functions in the biological environment with nanoscale precision, such as: nanoparticles, nanochips, nanorobots, quantum dots, nanovalves, etc. [2]. The dominant research and development fields in nanomedicine that are discussed in the rest of the paper focus on biopharmaceutics, antimicrobial properties, implants (implantable materials and devices), and diagnostic tools. 


\subsection{Biopharmaceutics}

The utilization of nanoparticles as drug delivery systems has already shown great success. As nano-enhanced drug delivery products already are a commercial reality, drug delivery is a dominant research field in nanomedicine. The development of nano-based drug delivery systems includes the use of nanoscale particles/molecules (that have unique medical effects according to their structure) to encapsulate the drug, deliver it to the target places and release it in controlled ways in order to repair damaged cells. Drug delivery systems are mainly used for treating neurological disorders (e.g., Alzheimer's and Parkinson's diseases), HIV/AIDS (Human Immunodeficiency Virus infection / Acquired Immune Deficiency Syndrome), and cancer. There are several nanoparticle drug delivery systems used in nanomedicine that come in various shapes and sizes: biological nanoparticles, polymersome nanoparticles, lipid-based drug delivery systems, micelle nanoparticles, etc. Nanovalves, tiny valves placed in the pores of nanostructures, are also used for drug delivery. Nanoscale silica and calcium phosphates are examples of materials that are used for encapsulating drugs in order to protect them during transportation inside the body [2]. Liposomes (and virosomes), nanosuspensions, polymeric nanoparticles, dendrimers, fullerenes, carbon nanotubes, inorganic nanoparticles, and nanoshells are examples of nanoscale particles/molecules that are developed to improve the bioavailability and pharmacokinetics of therapeutics. Engineered nanoparticles sensitive to certain $\mathrm{pH}$ values have proven to be the best means to deliver drugs avoiding invasive treatments. $\mathrm{pH}$ responsive nanoparticles in contact with the appropriate $\mathrm{pH}$ surroundings release the drug, which makes them of particular interest for drug delivery to specific cells, tissues or organs [10]. The utilization of gold nanoparticles conjugated with or without antibiotics holds the potential to improve the delivery (targeting and dosage) of antibiotics. The synthesis and utilization of gold nanoparticles are discussed in detail in [17], while the authors of [15] and [16] highlight the application of nanosilver particles in medicine. It is important to note that gold nanoparticles conjugated with conventional drugs can minimize side effects of drugs [14]. Likewise, silver nanoparticles show positive effects in various wound treatments (e.g., burns, chronic ulcers, toxic epidermal necrolysis, and pemphigus) which mainly consists in significantly shorter woundhealing time [16]. Copper oxide nanoparticles also show antimicrobial ability, which implies their application in disinfecting surfaces and medical devices as well as antimicrobial wound dressings, textiles and coatings [13]. Silver nanoparticles can be used for drug delivery of therapeutic agents in eye care for coating contact lenses [15]. Targeted delivery of peptides or DNA (deoxyribonucleic acid), as well as detection and photothermolysis of microorganisms and cancer cells are other examples of gold nanoparticles usage in biomedicine [17]. Cancer is one of the leading causes of death in the world, but at the same time, it is the largest therapeutic area where nano-enabled products have made major contributions.

Silver nanoparticles are used in the diagnosis and treatment of cancer. Similarly, the usage of gold nanoparticles functionalized with targeted specific biomolecules can effectively destroy cancer cells or bacteria [14]. In other words, gold nanoshells are being used to fight cancer in such way that, after entering tumor cells and applying radiation treatment, they absorb energy and heat up enough to kill the cancer cells with minimum harm to the surrounding healthy cells. Other factors can also be engaged in fighting cancer, like magnetic nanoparticles that bind to cancer cells present in the bloodstream, thus allowing the removal of cancer cells before they 
establish new tumors. Authors of [10] state the importance of magnetic nanoparticles utilization in magnetic field hyperthermia, which has shown to be a promising and more effective technology in cancer treatment. Thermosensitive yolk-shell nanoparticles were developed and presented in [9] as an innovative remote-controlled targeting drug delivery platform for multimodal imaging and combined cancer therapy, while authors of [18] present the possibilities of platinum nanoparticles utilization for treatment of several types of cancer. Camptothecin, Doxorubicin, Paclitaxel, Vincristine and Etoposide, as naturally occurring anti-cancer drugs, are presented and analyzed in [43]. Authors of [44] present albumin-based nano-enabled approaches for their potential use in cancer diagnosis and therapy. Shell-stacked nanoparticles with enhanced tumor penetration and uptake by cells in deep tumor tissue are presented in [45]. The antimicrobial, magnetic and optic activities of $\mathrm{Fe}_{3} \mathrm{O}_{4} \mathrm{Au}_{\mathrm{x}} \mathrm{Ag}_{\mathrm{y}}$ nanoparticles justify their usage in anticancer drug delivery since, at the same time, they enable to observe what happens to the cancerous cells without damaging healthy ones [19].

Based on the results achieved in fighting cancer, mainly the utilization of nanoparticles in cancer treatment, there is a belief that nanomedicine holds potential for defeating cancer for good [2]. The reason for this lies in the fact that nanodevices are faster and more sensitive than traditional drug delivery systems. They are able to deliver very strong drugs, with controlled release directly to a target place within the body without causing any side effects. Therefore, the benefits of targeted medicine consist of significantly decreased drug consumption, better patient care, less invasive drug delivery and cost-effective treatments [46]. However, there are numerous technical challenges for developing techniques for controlling sensitive drugs (targeting and triggering), nanochips for nanoparticle release, virus-like system creation for intracellular systems, etc. [8].

\subsection{Implants}

Nanomaterials and nanocomponents have increasingly been used as implantable materials and devices. Nanotechnology enables the development of nanomaterials and coatings that increase the adhesion, durability and life of implants in tissue repair and replacement applications. Nanostructures are also being used to prepare and improve tissue regeneration scaffolds. Alongside soft tissue implants, nanotechnology plays a central part in the evolution of hard tissue implants, bone substitute materials, and dental restoratives. Bone repair materials (e.g., calcium phosphate apatite, hydroxyapatite) and bioresorbable and smart materials (that respond to changes in the environment) are examples of nanomaterials used as structural implant materials [2]. As such, nanomaterials have greater biocompatibility and promote new bone growth [1]. Silver nanoparticles have proven to be an appropriate surface coating for stents and heart valves because of their antithrombogenic and antibacterial properties. Besides, their usage as catheter coating significantly helps to reduce bacterial growth. Coating contact lenses is another example of the applications of silver nanoparticles, thanks to their increased resistance to bacteria. The additional power of silver nanoparticles to maintain or increase the shear bond strength makes them suitable to be applied to dental instruments and bandages, as well as orthopedic and orthodontic implants and fixations [16].

The improvement of the orthopedic implant's lifespan can be also achieved by using carbon nanotubes [10]. Nevertheless, the utilization of implantable nanosensors enables more effective detection of a targeted chemical or physical attribute. Implantable nanomedical devices or na- 
nomachines deployed inside the human body can perform actions according to demands or be remotely controlled from the macro scale and over the Internet by an external user (a healthcare professional) [1]. Nanotechnology also enables the development of surgical instruments and robots that enable performing microsurgeries in a precise and accurate way. Surgery visualization can be improved by using nanocameras, while computers can be used to control the nano-sized surgical instruments. This way, surgery can be performed at tissue, genetic and cellular levels with a significantly reduced chance of mistakes. Although nanosurgery research is still in very early stages, it is a potential future application of nanoscience. Already commercially available nanoneedles, nanotweezers, nanorobots and precision lasers will contribute to the realization of the nanosurgery vision [47]. Nanomaterialbased medical devices have been presented in detail in [20]. The utilization of medical nanomachines for destroying kidney stones, nanorobots for cleaning lungs, arteries, teeth or nanorobots that support the regeneration of skin, organs (e.g., repairs of gastrointestinal and abdominal tissue) or bones (repair of bone defects and fractures) are closer to reality and widespread use than ever before [2], [4].

\subsection{Diagnostic tools}

The utilization of nanotechnology for clinical diagnostic purposes is referred to as nanodiagnostics. There are numerous types of nanoparticles that enable detection of pre-cancerous cells, a fragment of viruses, specific proteins, antibodies and other markers and indicators of disease [48]. Quantum dots, very small semiconductor particles, hold potential for creating disease detection systems that are more sensitive and accurate [2]. The utilization of novel sensors and lab-on-a-chip concepts based on nanotubes, nanowires, cantilevers or atomic force microscopy for diagnostic purposes improve the sensitivity and enable faster and more accurate diagnostics alongside reduced costs. For example, carbon nanotubes and gold nanoparticles used in sensors enable the detection of oral cancer indicators; nanoparticles called NanoFlares are used to discover cancerous cells in the bloodstream; and silver nanorods in a diagnostic system hold potential for separating viruses, bacteria and other microscopic elements of blood samples, etc. Furthermore, in vivo imaging can be performed using nanoparticle contrast agents, mainly for MRI (Magnetic Resonance Imaging) and ultrasound, or using miniature imaging devices like a pill containing a miniature video system that takes pictures throughout the whole digestive system. Iron oxide nanoparticles, thanks to their unique size and half-life, have proven to be the adequate contrast agent for improved detail in MRI, particularly for more accurate diagnosis of problems associated with the circulatory system [10]. Perfluorocarbon emulsion nanoparticles (PFC) help to increase the contrast of the image created by ultrasonography, improving its quality. This is of particular interest in medicine because ultrasonography is more economical than other noninvasive imaging technologies and can help with diagnosis, particularly when imaging tumors [10]. The utilization of fluorescent platinum nanoclusters as new biocompatible bioimaging probes for diagnostic purposes has been presented in [18]. Platinum nanomaterials have also been used for making molecular machines and motion-based detection methods. A more detailed analysis of diagnostic and therapeutic techniques using nanoparticles is performed in [20]. Hence, the application of nanoparticles and nanomaterials to imaging and visualization holds potential for faster, more sensitive and cost-effective diagnostic practices [4]. 


\section{INTERNET OF NANO THINGS (IONT) IN MEDICINE AND HEALTHCARE}

The Internet of Things (IoT) is a network of smart things/devices connected to the Internet and able to communicate with each other and with humans that has brought tremendous benefits in modern society. Further reduction of the size of devices to the nanoscale (from one to a few hundred $\mathrm{nm}$ ) and their connection to the Internet have enabled the appearance of a paradigm, namely the Internet of Nano Things (IoNT). The IoNT is based on the usage of nanomachines, small components able to perform simple processing, sensing and control tasks that are used for the development of nanoprocessors, nanomemories, nanobots and nanoclocks. Nanomachines are developed using the topdown approach (self-assembly of molecular components), bottom-up approach (synthesis of nanomaterials from atoms or molecules) or bio-hybrid approach (design based on molecular signaling) [42]. Nanonodes used in nanomedicine are nanomachines composed of control and storage unit, communication unit, power unit, and a variety of sensors and actuators. Interconnected nanonodes (devices able to sense, collect, process and store information) inside, on or outside the human body directly communicate via nanorouters and nano-micro interface devices with external devices, thus composing nanonetworks. Nanorouters, alongside data aggregation from nanonodes, also control the nanonodes by exchanging very simple control commands (on/off, sleep, read value, etc.). The remote control of the nanodevices over the Internet is performed via gateway devices (Fig. 1) [1], [49]-[51]. Regarding communication, radio frequency messaging in the $1-10 \mathrm{MHz}$ is a possible way to send a message into a body, while most cell communication uses chemical signals [2]. However, the uniqueness of nanodevices and nanonetworks implies the demand for new solutions for communicating with the outside world and between nanodevices. It is important to highlight that molecular communication is nano-electromagnetic and connects two nanodevices, transmitting and receiving electromagnetic radio frequency waves in the $\mathrm{THz}$ band [42], [50].

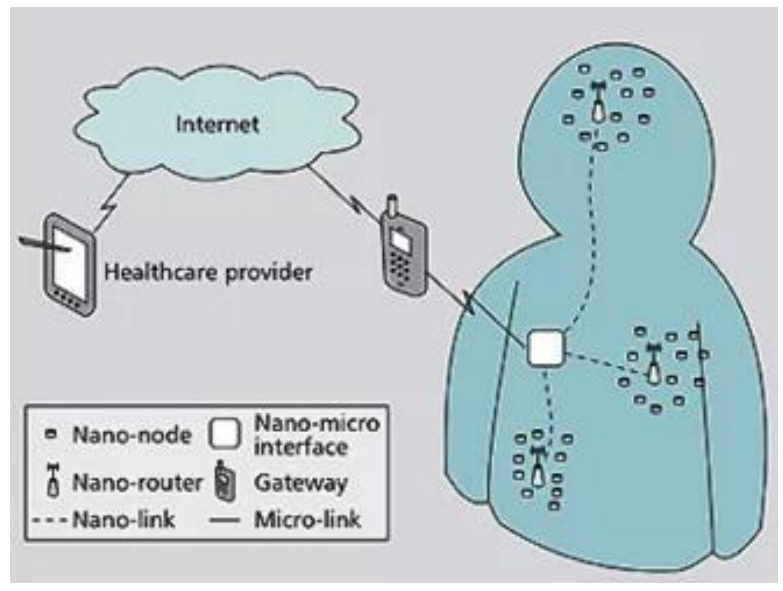

Fig. 1. Architecture of the IoNT in a healthcare application. Source: Akyildiz and Jornet [49].

Nanonetworks utilization in medicine and healthcare is most present in nanoscale surgeries, smart drug administration, and detection and management of the rapid spread of infectious diseases [50]. The IoNT paradigm enables doctors and healthcare providers to gain insights about the patient's current health condition, as well as remotely monitor and control any sudden change in the body through the nanosensors or nanorobots embedded within the patient's body. Some examples are monitoring the blood glucose level, delivering a drug in case of need or monitoring the biomarkers of cancer [51]. The inclusion of nanodevices and the IoNT in medicine and healthcare enables access to hardto-reach areas and vital information at a whole new level (molecular information) [1]. In this manner, it is possible to detect diseases, make an accurate diagnosis earlier and react faster than ever before, which significantly increases the chances of successful treatment and overcoming the diseases. 


\section{BENEFITS, CHALENGES, RISKS, AND CONCERNS REGARDING THE NANOTECHNOLOGY AND IONT UTILIZATION IN MEDICINE AND HEALTHCARE}

As can it be noted, the benefits of nanotechnology and the IoNT in medicine and healthcare are numerous. Earlier, faster, more accurate and sophisticated detection and diagnosis of different diseases, more effective disease treatment, enhanced monitoring of patient health status and prevention of diseases are the foundations of the next generation of medicine and healthcare, realized with the help of nanotechnology and the IoNT. Nanoparticles, nanosensors, nanorobots and other nanodevices connected in nanonetworks via the IoNT create a completely new environment for the revolutionization of healthcare and medicine in the $21^{\text {st }}$ Century. Nanodiagnostics, nanosurgery, regenerative medicine, nanodentistry and nanomedicine are expected to be in widespread use in years to come.

Despite the numerous benefits that the medical use of nanotechnology and the IoNT have to offer, there is a justified concern about their potential negative impacts. Nanoparticles can be made of almost any material through various processing techniques and be of any shape and structure. The function and applications of nanoparticles mostly depend on the nanoparticle's size [2]. Smaller nanoparticles are easier to clear from the bloodstream after the targeted nanoparticle therapy, but it is important to keep in mind that the smaller the particle, the more toxic it is. Besides, some types of nanomaterials may cause adverse reactions in patients. For this reason, nanotoxicology-as a research field-is increasingly important to understand the risks of using nanomaterials and the cost of the resulting damage [36].
Inadvertently or intentionally applied to the human body (through skin nodes, respiratory system, via ingestion or implanting), nanoparticles and nanomaterials may cause numerous health-related problems, as indicated in Fig. 2. For that reason, numerous research studies are devoted to the analysis of the toxicology of various nanoparticles applied to healthcare purposes: gold, silver, platinum, copper oxide, zinc oxide, silica and titania nanoparticles, quantum dots, manganese nanoparticles, fullerene, carbon nanotubes, inorganic nanoparticles, nanospheres, nanoshells and nanocapsules [18], [20], [24], [28], [29], [52]. Authors of [21] analyzed the environmental impact and potential health risks of $2 \mathrm{D}$ nanomaterials, mainly graphene-based materials, transition metal dichalcogenides and black phosphorus, mostly used for constructing electrodes and electronic, photovoltaic, and sensing devices. Due to the rapid development of nanotechnology and its utilization for healthcare purposes, there is a rising need for conducting toxicological studies of nanoparticles, nanomaterials, and nanosystems. Hence, both in-vitro and invivo studies of the biological effects of nanoparticles are mandatory. Some of the current methods used in nanotoxicity assessment are presented in [27].

Therefore, regarding the intentional use of nanoparticles and nanomaterials for healthcare purposes, it is essential to find a balance between the safety of the nanoparticles and nanomaterials that are used and the efficiency of the treatment. Different aspects of toxicology should be considered when nanoparticles and nanomaterials are being used for medical diagnosis and treatment. Hence, the main challenge for nanotoxicology is to determine the properties of nanoparticles that may cause significant adverse health effects when being applied to the patient during diagnostic or treatment procedures [30]. 


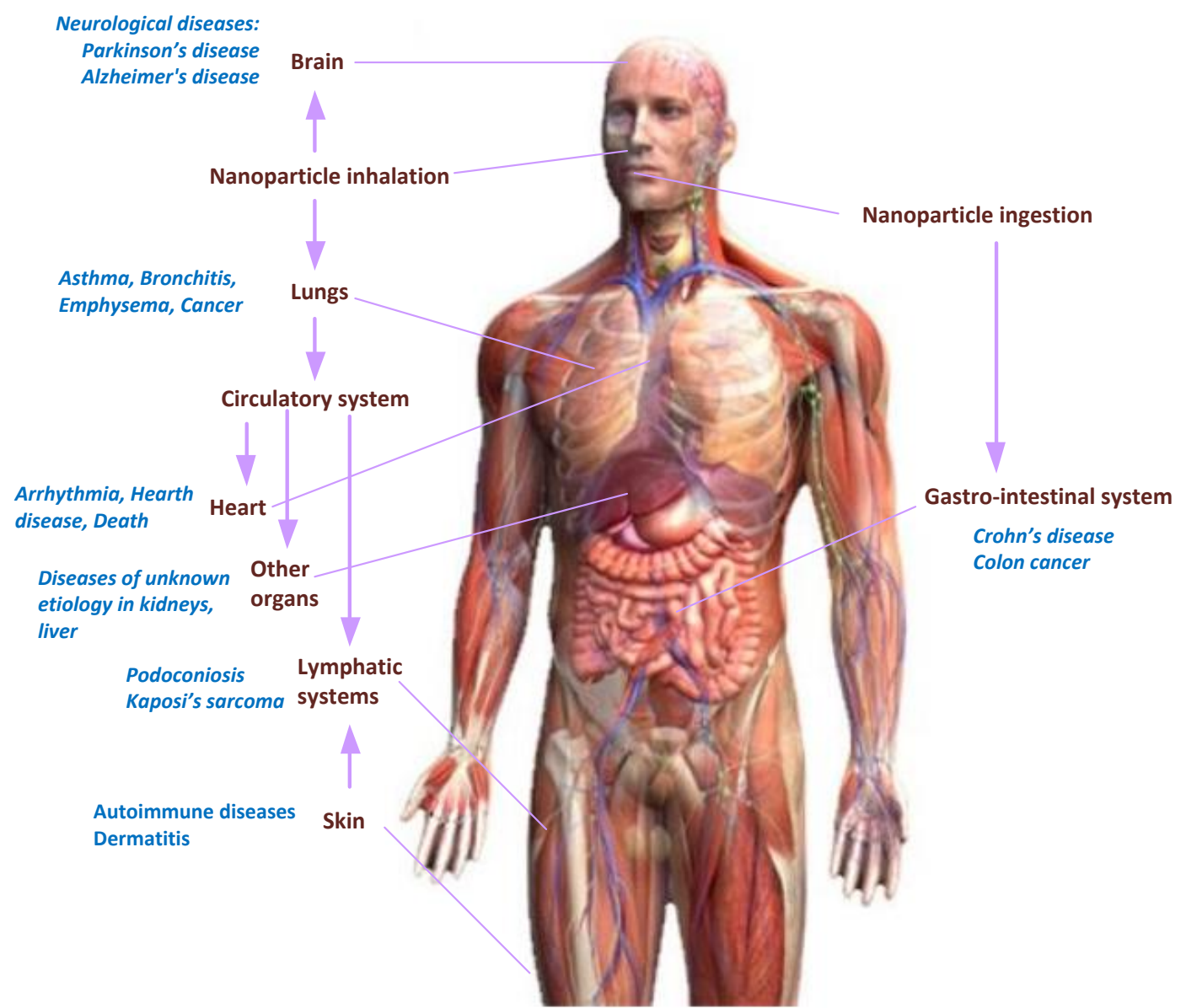

Fig. 2. Potential harmful effects of nanoparticles to human health. Source: Maksimović and Omanović-Mikličanin [36].

There are numerous organizations that attempt to address nanotechnology toxicity to humans and the environment, such as the Organisation for Economic Cooperation and Development (OECD), the National Institute for Occupational Safety and Health (NIOSH), the EU NanoSafety Cluster, the Federal Institute for Materials Research and Testing (BAM), the Federal Ministry of Education and Research (BMBF), Modena Cost and others [24].

However, there are no particular regulations on nanoparticles apart from the existing ones covering similar materials in bulk. This represents the main challenge and obstacle in the evolution of nanotechnology. The complexity of nanoparticles, nanomaterials, and nanotechnology in general is the main reason for the lack of regulation and standards covering this scientific and research field. Although there is no specific regulatory framework for nanotechnology-based products, authors of [26] presented their regulatory roadmap for nanotechnology-based machines. In order to become more aware of the potential harmful effects of nanotechnology on human health and the environment, extensive studies on nanomaterials' interaction with biological systems and international collaborative research are required. In addition, there is a need to work extensively on developing nanospecific regulations for developing and labeling nanoproducts [53]. However, it is important to mention some of the standard-setting groups that are involved in developing nanotechnology standards, such as the International Standardization Organization (ISO) Technical Committee (TC) 229 on Nanotechnologies, the ASTM (American Society for Testing and Materi- 
als) the International Committee E56 (Nanotechnology), the International Electrotechnical Commission Technical Committee 113 (Nanotechnology Standardization for Electrical and Electronics Products and Systems), and the Institute of Electrical and Electronics Engineers' Nanotechnology Council [53].

In order to reduce the negative aspects of nanotechnology, recent research is being focused on moving towards green nanotechnology. Green nanotechnology is based on green chemistry principles implemented in designing nanoscale products, the development of nanomaterial production methods and nanomaterials utilization. Even though most of the potential of green nanotechnology solutions is still in the lab/startup phase [36], green nanotechnology is expected to bring numerous benefits across diverse sectors, including medicine and healthcare, mostly reducing the negative impacts of nanotechnology on human health and the environment. The production of nanoparticles using green chemistry synthesis routes is environmentally friendly and non-toxic, as well as cost-effective. The synthesis of nanoparticles can be performed by plants, algae, bacteria, yeast, fungi, and human cells [37], [40], [54]. Authors of [39] present a variety of green methods for the synthesis of iron nanoparticles based on plant extracts, fungi, bacteria, amino acids, etc. There are also numerous examples of using a variety of plants for the development of nanoparticles, silver and gold nanoparticles particularly. For example, leaf extracts of lemongrass, aloe vera and tamarind can be used for forming silver and gold nanoparticles [37]. Besides, authors of [11] present ways to prepare gold nanoparticles by using a natural biomaterial, egg shell membrane, high-power ultrasound, sodium dehydrate, and applying sunlight irradiation methods or exposing edible mushroom to sunlight. A more detailed analysis of green nanoparticles synthesis, their characteristics and applications are given in
[38] and [54], where that green approach is clearly presented and mostly focused on the synthesis of metallic and bimetallic nanoparticles. Green synthesized nanoparticles possess anticancer, antimicrobial and imaging properties what make them suitable for diagnostic applications, drug delivery and anticancer activities [38], [54]. In addition, green synthesis of nanoparticles is less polluting and based on the utilization of natural chemical-free products; then, the toxicity of nanoparticles is reduced compared to the "traditionally" produced nanoparticles. Low energy use and environmental impact alongside significantly less side effects are additional benefits of green synthesis of nanoparticles. However green nanoparticles are yet to be explored and improved and promise to bring about a huge potential in the treatment of a variety of diseases.

At the same time, the IoNT that holds the potential to revolutionize healthcare more than anything else before, also brings risks and challenges that must be considered. The IoNT enables to gain better insights into health conditions, remotely monitor and control, and timely and accurately respond to unexpected changes in the human body. Nevertheless, the primary concerns are security and privacy issues. Health-related data are quite sensitive and they have to be properly protected. To reduce the risk of any malicious attacks (e.g., disruption of medical applications that can harm or kill through drug delivery and radio communication [31]), a strong network security infrastructure for all ranges of communication (from nanodevices, router and gateway, further to the Cloud) is mandatory. Existing security mechanisms and techniques are not suitable to secure nanodevices in nanonetworks because they operate in the $\mathrm{THz}$ band. The fact that current security solutions are not suitable for protecting the IoNT implies the necessity of new and appropriate security and privacy framework and mechanisms, presented in vari- 
ous research works [31]-[34], [51]. Some of the proposed solutions are: checking the integrity of information by using checksum algorithms, using encryption algorithms to code information before transferring between nanodevices, critical data hiding algorithms, and multi-layer authentication to guarantee only authenticated user can access nanonetworks [51].

Table 1 presents an attempt to summarize the Strengths, Weaknesses, Opportunities, and Threats of nanotechnology and IoNT utilization in medicine and healthcare.

In summary, the concerns regarding nanotechnology and IoNT utilization in medicine and healthcare, besides technical are also social, economic and ethical, such as:

- Reducing the gap between humans and robots/computers;

- The control of nanotechnology applied for medical purposes;

- The evolution of nanomedicine and the provision of the same level and quality of nano-based healthcare to all, irrespective of ethnicity, race, gender or political viewpoints;

- The nanotoxicity of nanoparticles and nanomaterials applied in healthcare;

- The possibilities of using novel technological approaches to harm people; and

- Standards and regulatory issues.

Table 1. SWOT analysis - Nanotechnology and the IoNT in medicine and healthcare

\begin{tabular}{|c|c|}
\hline Strengths & Weaknesses \\
\hline $\begin{array}{l}\text { Earlier, faster and more accurate diagnostic processes } \\
\text { Innovative and adequate therapies and painless treatments } \\
\text { Reduced negative effects of drugs and surgical procedures } \\
\text { New drugs and drug delivery systems } \\
\text { Faster, smaller, highly-sensitive diagnostic and treatment } \\
\text { tools (e.g. nanorobots, nanoneedles, nanotweezers, nanocam- } \\
\text { eras, etc.) } \\
\text { Smart nanodevices connected to the Internet } \\
\text { Real-time and remote monitoring of disease and treatments } \\
\text { via the IoNT } \\
\text { Significantly reduced medical and healthcare cost }\end{array}$ & $\begin{array}{l}\text { Persisting lack of proper knowledge regarding nanoparticles } \\
\text { and nanomaterials reactions inside the human body } \\
\text { Possible toxicity of nanoparticles and nanomaterials } \\
\text { Privacy and security issues regarding health-related data } \\
\text { Lack of standards and regulations } \\
\text { Immature public awareness and understanding of nanotech- } \\
\text { nology and the IoNT (ethical concerns and trust issues) }\end{array}$ \\
\hline Opportunities & Threats \\
\hline $\begin{array}{l}\text { Significant progress in fighting numerous unsolved medical } \\
\text { problems and diseases, such as cancer } \\
\text { Reduction of mortality and morbidity rates, extension of } \\
\text { patients' lives }\end{array}$ & $\begin{array}{l}\text { Security and privacy issues regarding nanonetworks are not } \\
\text { fully addressed } \\
\text { Concerns regarding control over nanotechnologies applied in } \\
\text { medicine and healthcare }\end{array}$ \\
\hline $\begin{array}{l}\text { Moving towards green nanotechnology and green IoNT holds } \\
\text { the potential to create smarter, safer, and more sustainable } \\
\text { medical practices } \\
\text { Development of computational models that will predict } \\
\text { toxicity and other potential side effects of nanomaterials } \\
\text { used in medical and healthcare purposes based on the nano- } \\
\text { particles structures, } \\
\text { Maximization of the return of Research and Development } \\
\text { investments }\end{array}$ & $\begin{array}{l}\text { The lack of proper mechanisms opens a potential utilization } \\
\text { of nanotechnology and the IoNT to harm or kill } \\
\text { Nanoparticles' and nanomaterials' toxicological behavior }\end{array}$ \\
\hline
\end{tabular}




\section{CONCLUSIONS}

Nanotechnology, as the Second Industrial Revolution, has seemingly limitless potential to revolutionize all aspects of our lives. However, the most significant benefits can be expected in medicine and healthcare, where nanotechnology already shows numerous advantages. Significantly enhanced disease diagnosis and treatment by means of nanotechnology promise to create a completely new generation of medicine and healthcare. Implementing IoT concepts on the nanoscale contributes to more effective and accurate monitoring of health conditions, and consequently appropriate, adequate, and timely actions. Despite the numerous benefits of nanomedicine and the IoNT, there are also issues that have to be seriously taken into consideration. Nanotoxicity, privacy and security issues are the main concerns and main obstacles on the road to full implementation of nanotechnology and the IoNT in medicine and healthcare. Moving towards a greener future, increasing awareness regarding nanotechnology utilization, successfully dealing with nanotoxicity issues and developing security and privacy mechanisms in IoNT concepts promise that nanotechnology and the IoNT will successfully replace traditional medical and healthcare practices and techniques. A future in which green (nano) technologies and green chemistry principles are fully implemented will importantly contribute to revolutionizing the healthcare of the $21^{\text {st }}$ Century, making it more precise, on-time, accessible and affordable than ever before. Healthier and longer lives are the main aims of the next generation of medicine and healthcare. Nanotechnology and the IoNT will undoubtedly play a major role in accomplishing this goal.

\section{REFERENCES}

[1] E. Omanović--Mikličanin, M. Maksimović, and V. Vujovic,, "The Future of Healthcare:
Nanomedicine and Internet of Nano Things," Folia Medica Fac. Med. Univ. Saraeviensis, vol. 50, no. 1, pp. 23-28, 2015.

[2] R. R. Letfullin and T. F. George, "Introduction to Nanomedicine," in Computational Nanomedicine and Nanotechnology, Cham: Springer International Publishing, 2016, pp. $1-61$.

[3] K. A. Howard, T. Vorup-Jensen, and D. Peer, Nanomedicine. New York, NY: Springer New York, 2016.

[4] Y. Ge, S. Li, S. Wang, and R. Moore, Nanomedicine: Principles and Perspectives. New York, NY: Springer New York, 2014.

[5] Joint European Comission/ETP nanomedicine, "Roadmaps in nanomedicine towards 2020," 2009.

[6] B. Bogdanov, R. Raykova, Y. Hristov, and P. Ivanov, "Nanostructured materials. Selected Synthesis Methods," Научни трудове на Русенския Университет, vol. 51, no. 9.1, pp. 96-102, 2012.

[7] N. Rajput, "Methods of preparation of nanoparticles-A review," Int. J. Adv. Eng. Technol., vol. 7, no. 4, pp. 1806-1811, 2015.

[8] S. L. Pal, U. Jana, P. K. Manna, G. P. Mohanta, and R. Manavalan, "NanoparticlesAn Overview of Preparation and Characterization," J. Appl. Pharm. Sci., vol. 1, no. 6, pp. 228-234, Nov. 2011.

[9] S. Shen, B. Ding, S. Zhang, X. Qi, K. Wang, J. Tian, Y. Yan, Y. Ge, and L. Wu, "Nearinfrared light-responsive nanoparticles with thermosensitive yolk-shell structure for multimodal imaging and chemo-photothermal therapy of tumor," Nanomedicine Nanotechnology, Biol. Med., vol. 13, no. 5, pp. 1607-1616, Jul. 2017.

[10] C. M. D'Almeida and B. J. Roth, "Medical Applications of Nanoparticles," Department of Physics, Oakland University, Rochester, Michigan

[11] A. Khan, R. Rashid, G. Murtaza, and A. Zahra, "Gold Nanoparticles: Synthesis and Applications in Drug Delivery," Trop. J. Pharm. Res., vol. 13, no. 7, p. 1169, Sep. 2014.

[12] J. Marijnissen and L. Gradoń, "Nanoparticles in Medicine and Environment: Inhalation and Health Effects," J. Aerosol Med. Pulm. Drug Deliv., vol. 23, no. 5, pp. 339-341, Oct. 2010.

[13] M. Grigore, E. Biscu, A. Holban, M. Gestal, and A. Grumezescu, "Methods of Synthesis, Properties and Biomedical Applications of CuO Nanoparticles," Pharmaceuticals, vol. 9, no. 4, p. 75, Nov. 2016.

[14] K. Alaqad and T. A. Saleh, "Gold and Silver Nanoparticles: Synthesis Methods, Characterization Routes and Applications towards Drugs," J. Environ. Anal. Toxicol., vol. 6 , no. 4, pp. 525-2161, 2016. 
[15] M. Xing, L. Ge, M. Wang, Q. Li, X. Li, and J. Ouyang, "Nanosilver particles in medical applications: synthesis, performance, and toxicity," Int. J. Nanomedicine, vol. 9, p. 2399, May 2014.

[16] M. Murphy, K. Ting, X. Zhang, C. Soo, and Z. Zheng, "Current Development of Silver Nanoparticle Preparation, Investigation, and Application in the Field of Medicine," $J$. Nanomater., vol. 2015, pp. 1-12, 2015.

[17] M. Shah, V. Badwaik, Y. Kherde, H. K. Waghwani, T. Modi, Z. P. Aguilar, H. Rodgers, W. Hamilton, T. Marutharaj, C. Webb, M. B. Lawrenz, and R. Dakshinamurthy, "Gold nanoparticles: various methods of synthesis and antibacterial applications.," Front. Biosci. (Landmark Ed., vol. 19, pp. 1320-44, Jun. 2014.

[18] D. Pedone, M. Moglianetti, E. De Luca, G. Bardi, and P. P. Pompa, "Platinum nanoparticles in nanobiomedicine," Chem. Soc. Rev., vol. 46, no. 16, pp. 4951-4975, 2017.

[19] E. K. Fodjo, K. M. Gabriel, B. Y. Serge, D. Li, C. Kong, and A. Trokourey, "Selective synthesis of $\mathrm{Fe}_{3} \mathrm{O}_{4} \mathrm{Au}_{\mathrm{x}} \mathrm{Ag}_{\mathrm{y}}$ nanomaterials and their potential applications in catalysis and nanomedicine," Chem. Cent. J., vol. 11, no. 1, p. 58, Dec. 2017.

[20] T. Devasena, "Diagnostic and Therapeutic Nanomaterials," Springer, 2017, pp. 1-13.

[21] M. Fojtů, W. Z. Teo, and M. Pumera, "Environmental impact and potential health risks of $2 \mathrm{D}$ nanomaterials," Environ. Sci. Nano, vol. 4, no. 8, pp. 1617-1633, 2017.

[22] M. S. Bakshi, "Nanotoxicity in Systemic Circulation and Wound Healing," Chem. Res. Toxicol., vol. 30, no. 6, pp. 1253-1274, Jun. 2017.

[23] J. Wolfram, M. Zhu, Y. Yang, J. Shen, E. Gentile, D. Paolino, M. Fresta, G. Nie, C. Chen, H. Shen, M. Ferrari, and Y. Zhao, "Safety of Nanoparticles in Medicine.," Curr. Drug Targets, vol. 16, no. 14, pp. 1671-81, 2015.

[24] B. Viswanath and S. Kim, "Influence of Nanotoxicity on Human Health and Environment: The Alternative Strategies," in Reviews of Environmental Contamination and Toxicology Volume 242, Springer, 2016, pp. 61-104.

[25] A. Pourmand and M. Abdollahi, "Current Opinion on Nanotoxicology," DARU J. Pharm. Sci., vol. 20, no. 1, p. 95, 2012.

[26] V. Limaye, G. Fortwengel, and D. Limaye, "Regulatory roadmap for nanotechnology based medicines," Int. J. Drug Regul. Aff., vol. 2, no. 4, pp. 33-41, 2014.

[27] P. Takhar and S. Mahant, "In vitro methods for nanotoxicity assessment: advantages and applications," Arch Appl Sci Res, vol. 3, no. 2, pp. 389-403, 2011.

[28] M. Umair, I. Javed, M. Rehman, A. Madni, A. Javeed, A. Ghafoor, and M. Ashraf, "Nanotoxicity of Inert Materials: The Case of Gold, Silver and Iron.," J. Pharm. Pharm. Sci., vol. 19, no. 2, pp. 161-80, 2016.

[29] C. Ostiguy, B. Soucy, G. Lapointe, C. Woods, L. Ménard, and M. Trottier, Health Effects of Nanoparticles - Second Edition, IRSST Communications Division, 2008.

[30] D. S. Anderson, M. J. Sydor, P. Fletcher, and A. Holian, "Nanotechnology: The Risks and Benefits for Medical Diagnosis and Treatment," J. Nanomed. Nanotechnol., vol. 7, no. 4, p. e143, 2016.

[31] F. Dressler and F. Kargl, "Security in nano communication: Challenges and open research issues," in 2012 IEEE International Conference on Communications (ICC), 2012, pp. 6183-6187.

[32] F. Dressler and F. Kargl, "Towards security in nano-communication: Challenges and opportunities," Nano Commun. Netw., vol. 3, no. 3, pp. 151-160, Sep. 2012.

[33] V. Vassiliou, "Security Issues in Nanoscale Communication Networks," in 3rd NaNoNetworking Summit, 2011.

[34] I. F. Akyildiz, J. M. Jornet, and M. Pierobon, "Nanonetworks," Commun. ACM, vol. 54, no. 11, p. 84, Nov. 2011.

[35] F. Mohammad and H. A. Al-Lohedan, "Chitosan-Mediated Layer-by-Layer Assembling Approach for the Fabrication of Biomedical Probes and Advancement of Nanomedicine," in Nanocellulose and Nanohydrogel Matrices, Weinheim, Germany: Wiley-VCH Verlag GmbH \& Co. KGaA, 2017, pp. 91-124.

[36] M. Maksimović and E. Omanović-Mikličanin, "Towards green nanotechnology: maximizing benefits and minimizing harm," in $C M B E B I H$ 2017, Springer, 2017, pp. 164-170.

[37] K. Parveen, V. Banse, and L. Ledwani, "Green synthesis of nanoparticles: Their advantages and disadvantages," in AIP Conference Proceedings, 2016, vol. 1724, no. 1, p. 20048.

[38] S. Kumar, V. Lather, and D. Pandita, "Green synthesis of therapeutic nanoparticles: an expanding horizon," Nanomedicine, vol. 10, no. 15, pp. 2451-2471, Aug. 2015.

[39] S. Saif, A. Tahir, and Y. Chen, "Green synthesis of iron nanoparticles and their environmental applications and implications," Nanomaterials, vol. 6, no. 11, p. 209, 2016.

[40] P. Velusamy, G. V. Kumar, V. Jeyanthi, J. Das, and R. Pachaiappan, "Bio-Inspired Green Nanoparticles: Synthesis, Mechanism, 
and Antibacterial Application," Toxicol. Res., vol. 32, no. 2, pp. 95-102, Apr. 2016.

[41] G. S. Nikolić, M. D. Cakić, S. Glišić, D. J. Cvetković, Ž. J. Mitić, and D. Z. Marković, "Study of Green Nanoparticles and Biocomplexes Based on Exopolysaccharide by Modern Fourier Transform Spectroscopy," in Fourier Transforms - High-tech Application and Current Trends, InTech, 2017.

[42] A. Nayyar, V. Puri, and D.-N. Le, "Internet of Nano Things (IoNT): Next Evolutionary Step in Nanotechnology," Nanosci. Nanotechnol., vol. 7 , no. 1 , pp. $4-8,2017$

[43] S. Ni, "Nanoparticles carrying natural product for drug delivery," J. Drug Deliv. Ther., vol. 7, no. 3, pp. 73-75, 2017.

[44] B. Bhushan, V. Khanadeev, B. Khlebtsov, N. Khlebtsov, and P. Gopinath, "Impact of albumin based approaches in nanomedicine: Imaging, targeting and drug delivery," Adv. Colloid Interface Sci., vol. 246, pp. 13-39, Aug. 2017.

[45] J. Chen, J. Ding, Y. Wang, J. Cheng, S. Ji, X. Zhuang, and $X$. Chen, "Sequentially Responsive Shell-Stacked Nanoparticles for Deep Penetration into Solid Tumors," Adv. Mater., vol. 29, no. 32, p. 1701170, Aug. 2017.

[46] A. P. Nikalje, "Nanotechnology and its Applications in Medicine," Med. Chem. (Los. Angeles)., vol. 5, no. 2, pp. 81-89, 2015.

[47] B. Asiyanbola and W. Soboyejo, "For the Surgeon: An Introduction to Nanotechnology," J. Surg. Educ., vol. 65, no. 2, pp. 155-161,
Mar. 2008.

[48] K. K. Alharbi and Y. A. Al-sheikh, "Role and implications of nanodiagnostics in the changing trends of clinical diagnosis," Saudi J. Biol. Sci., vol. 21, no. 2, pp. 109-117, Apr. 2014.

[49] I. Akyildiz and J. Jornet, "The Internet of nano-things," IEEE Wirel. Commun., vol. 17, no. 6, pp. 58-63, Dec. 2010.

[50] Y. Bhatt and C. Bhatt, "Internet of Things in HealthCare," in Internet of Things and Big Data Technologies for Next Generation Healthcare, Springer, 2017, pp. 13-33.

[51] H. Ezz El-Din and D. H. Manjaiah, "Internet of Nano Things and Industrial Internet of Things," in Internet of Things: Novel Advances and Envisioned Applications, vol. 25, D. P. Acharjya and M. K. Geetha, Eds. Cham: Springer International Publishing, 2017, pp. 109-123.

[52] Y. N. Chang, M. Zhang, L. Xia, J. Zhang, and G. Xing, "The Toxic Effects and Mechanisms of $\mathrm{CuO}$ and $\mathrm{ZnO}$ Nanoparticles," Materials (Basel)., vol. 5, no. 12, pp. 2850-2871, Dec. 2012.

[53] A. H. Idris, "Nanotechnology Standards development," in National Workshop on Nanosafety and Regulatory Aspect of Nanotechnology, 2014.

[54] D. Nath and P. Banerjee, "Green nanotechnology - A new hope for medical biology," Environ. Toxicol. Pharmacol., vol. 36, no. 3, pp. 997-1014, Nov. 2013. 